\title{
Estrategias mnemotécnicas para la enseñanza y el aprendizaje del vocabulario del inglés
}

\author{
Rosa María Jiménez
}

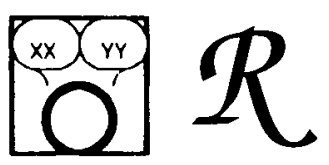

La enseñanza de procedimientos relacionados con el "aprender a aprender» es clave en la enseñanza de lenguas extranjeras. Este artículo revisa y clasifica un conjunto de técnicas que permiten al aprendiz utilizar mejor la memoria comprensiva.

\section{INTRODUCCION}

En la historia de la metodología de la enseñanza del inglés, el enfoque del vocabulario se ha caracterizado por la casi total ausencia de planteamientos tanto teóricos, como prácticos. La mayoría de los métodos, desde el siglo pasado hasta nuestros días, no dedican un apartado especial para explicar cómo se debe enseñar el vocabulario. El breve repaso que realizamos a continuación, a cuatro de los métodos más conocidos, nos ofrece un ejemplo claro de cómo el enfoque de enseñanza se ha concentrado invariablemente en la morfología y la sintaxis.

En el método de Gramática y Traducción, muy popular hasta la mitad de este siglo, el énfasis recae en la presentación de las reglas gramaticales de la lengua extranjera, y en la práctica de la traducción de la lengua materna (L1) a la lengua objeto de aprendizaje (L2). La enseñanza del vocabulario consiste meramente en la presentación , mediante la lengua escrita, de listas de palabras con su correspondiente traducción. La finalidad no es otra que la comprensión de los textos y su traducción posterior.

Comparado con el anterior, el Método Directo supone una revolución en el enfoque de enseñanza, sin embargo, tampoco encontramos directrices concretas sobre las estrategias a utilizar. Las orientaciones se deducen de su premisa fundamental: presentar las palabras directamente en la lengua meta (L2). El alumno debe asociar dicha lengua con la acción, el objeto, el mimo, los gestos o el contexto.

En el Método Audiolingual se subraya la importancia de la audición de estructuras sintácticas contenidas en diálogos, y la práctica de las mismas, a través de repeticiones orales tipo «drills». El objetivo es que el aprendiz fije el sistema de la lengua mediante hábitos lingüísticos. La enseñanza explícita del vocabulario no se contempla como tal. Las palabras se memorizan insertas en cadenas de estructuras sintácticas descontextualizadas.

No se puede afirmar que la implantación del Método Comunicativo en la década de los ochenta, conlleve una mejoría notable en lo que concierne al vocabulario, 
puesto que el papel que ocupa éste en los planteamientos metodológicos sigue siendo marginal. La única diferencia es que, en este método, se subordina a la enseñanza de funciones comunicativas más que a las estructuras. Se sobreentiende que el estudiante aprende las palabras de forma automática e inconsciente, a través de la práctica de actividades.

Como consecuencia de esta ausencia de planteamientos, no es de extrañar que muchos de los libros de texto utilizados en el sistema educativo español, no contengan apenas sugerencias de las posibles estrategias a la hora de enseñar $o$ aprender el vocabulario, y que en numerosas ocasiones, los profesores opten por dar al alumno la traducción directa de listas de palabras que acompañan a cada unidad del libro de texto.

Afortunadamente, el panorama que acabamos de esbozar ha comenzado a cambiar . A partir de la década de los ochenta, debido en gran parte a la importancia que cobran los estudios semánticos, y a la investigación empírica que se deriva de los mismos, se detecta un gran interés por desarrollar una metodología específica para el aprendizaje y enseñanza del vocabulario. Esta nueva actitud se canaliza en cinco corrientes de estudios: bibliografías especializadas, estudios de adquisición del vocabulario, estudios de enseñanza del vocabulario, materiales de enseñanza, y lexicografía. (Maiguashca 1993).

\section{OBJETIVOS}

En este trabajo nos proponemos aportar nuestra contribución a los estudios de enseñanza del vocabulario, mediante la adaptación al aprendizaje y enseñanza del vocabulario del inglés, de algunas de las técnicas y recursos que se utilizan para desarrollar la memoria en el campo de la psicología.

\section{JUSTIFICACION DE ESTE TRABAJO}

Pensamos que el vocabulario es un aspecto esencial para el desarrollo de la competencia comunicativa en una lengua extranjera. Meara (1984) ha señalado la elevada frecuencia de los errores de léxico en la interlengua de aprendices de idiomas. La falta de dominio en este área tiene graves repercusiones en la comunicación. Los estudios de Lindell (1973), Burt y Kiparsky (1972), Roche (1983), Palmberg (1987), Jiménez (1992), entre otros, han demostrado que los errores de vocabulario son los más numerosos y los más serios desde el punto de vista de la comunicación.

A pesar de que los últimos diez años se han caracterizado por el incremento tanto de estudios teóricos, como de nuevos materiales de enseñanza, todavía prevalece la necesicidad de explorar nuevas técnicas para introducir y consolidar el vocabulario de una manera eficaz. Especialmente, existen lagunas en lo que se refiere al uso de la memoria para desarrollar estrategias de aprendizaje y enseñanza. Nuestra finalidad es destacar su papel en el aprendizaje de un idioma, mostrando algunas de las muchas aplicaciones que puede ofrecer. Para ello, nos centramos en adecuar al inglés varias técnicas mnemotécnicas utilizadas en la vida cotidiana.

Desde nuestro punto de vista, la utilización de estas técnicas — siempre como complemento de otras_ puede ayudar, no sólo a memorizar palabras, sino, de paso, a desarrollar la autonomía de aprendizaje del alumno, además de mejorar su memoria. A pesar de ser un factor imprescindible en todo el aprendizaje, actualmente es un aspecto poco trabajado en el aula. No obstante, la investigación existente en este campo concreto, resalta de manera contundente el papel de la memoria en el aprendizaje de una lengua extranjera. En particular, los investigadores señalan cómo aquellos individuos que utilizan recursos mnemotécnicos mejoran su capacidad retentiva, tanto en términos cualitativos, como cuantitativos. (Pressley 1979, Thompson 1987, Tang 1991, Wang \& Thomas 1992, Carrell 1992). 
Las técnicas y recursos que proponemos en este trabajo, no se adscriben a ningún método, ni responden a un modelo teórico o descriptivo en particular, puesto que hasta la fecha no han sido sistematizadas para el uso de la enseñanza de un idioma. En nuestra opinión, el vocabulario, más que ningún otro componente, permite la libertad de una aproximación ecléptica, siempre que ésta sea sistemática y esté bien fundamentada. Este planteamiento permite al profesor elegir y emplear las técnicas que considere adecuadas a cada momento, sin supeditar su enseñanza a las directrices de un método concreto. Los alumnos agradecen la variedad, y las estrategias que proponemos se adaptan perfectamente a tal fin.

El método que seguiremos para la exposición de nuestro trabajo es el siguiente. En una primera parte, definimos el concepto de estrategia mnemotécnica, explicamos brevemente sus fundamentos y clasificamos el tipo de técnicas. Posteriormente, en una segunda parte, explicamos trece ejemplos de adecuación de estas técnicas mnemotécnicas al aprendizaje y enseñanza del inglés. Es necesario precisar que nos limitamos a presentar técnicas mnemotécnicas más pensadas para el aprendizaje individual que para el discurso interactivo. Se trata de una alternativa más, entre otras muchas, que el profesor puede utilizar para enseñar al alumno cómo abordar el aprendizaje de palabras. Por otra parte, las limitaciones de espacionos obligan a presentar ejemplos muy breves. No obstante, la aparente descontextualización que pueda darse en alguno de los ejemplos obedece más bien a la idiosincracia de estas técnicas, que son, como se explica más adelante, recursos muy puntuales que el alumno puede utilizar una vez entrenado previamente

\section{DEFINICIONES OPERATIVAS}

Highbee (1977) define el término mnemotécnico como un sistema, fórmula , regla o estrategia que se utiliza para ayudar a memorizar algo. Hernández Pina (1990) delimita el término al contexto de aprendizaje en el aula y las define como reglas mnemotécnicas que recurren al uso de ciertas combinaciones, relaciones y asociaciones de ideas o artificios con objeto de facilitar la retención por más tiempo.

En este trabajo, nos referimos a los términos recurso, técnica o estrategia mnemotécnica indistintamente; por tales acepciones entendemos las fórmulas, reglas o soluciones potenciales que podemos utilizar de forma voluntaria para ayudar a la memoria en el aprendizaje del vocabulario del inglés.

\section{FUNDAMENTOS DE LAS TÉCNICAS MNEMOTÉCNICAS}

Las técnicas mnemotécnicas se basan en principios de la psicología : utilizan combinaciones, relaciones y asociaciones de ideas, a la vez que explotan nuestras capacidades visuales, mentales y auditivas.

El uso sistemático de estas técnicas tiene efectos positivos no sólo en el aprendizaje de un idioma, sino en cualquier aprendizaje. Por una parte, nos brindan la oportunidad de descubrir el modo cómo funciona nuestra mente, por otra, favorecen una memorización rápida y duradera y mejoran la memoria a través de la retroalimentación que ésta recibe mediante el continuo uso de recursos externos. También permiten integrar el material nuevo en las unidades cognitivas ya existentes en nuestra mente, a la vez que facilitan la asociación de ideas, palabras, sonidos o reglas. A todo esto hay que sumar el hecho de que, una vez aprendidas, las técnicas mnemotécnicas son difíciles de olvidar, puesto que como ya hemos mencionado, se basan en los mismos mecanismos que rigen el funcionamiento del cerebro humano.

Además de los beneficios apuntados, es posible destacar otros aspectos interesantes, como por ejemplo, su adaptabilidad tanto a las necesidades individuales de 
aprendizaje, como a los distintos contextos y situaciones en que se produce aquél. No menos importante es el carácter lúdico que aportan al aprendizaje; el estudiante, al hacer uso de mecanismos poco corrientes de memorización, se desinhibe y disfruta, lo que le posibilita un aprendizaje gratificante, y a la larga, más efectivo. No obstante, este carácter lúdico no implica una ausencia de esfuerzo. El empleo de estrategias mnemotécnicas requiere algo más que una simple memorización; en los primeros estadios de aprendizaje y especialmente, si no estamos habituados a su uso, nuestra mente tiene que esforzarse para llevar a cabo las tareas de relación y asociación entre elementos conocidos y desconocidos.

\section{TIPOS DE TÉCNICAS MNEMOTÉCNICAS}

Las técnicas y estrategias mnemotécnicas son numerosas y variadas. A pesar de que no resulta fácil sistematizarlas, es posible agruparlas en torno a algunos puntos en común. En primer lugar, destaca el hecho de que prácticamente todas se basan bien en asociaciones o en manipulaciones de elementos visuales y verbales. Así, encontramos técnicas que emplean la imagen o el espacio asociados a algo que se desea recordar; otras que utilizan estímulos auditivos como sonidos, palabras rimadas o frases en las que interviene el ritmo. La mayoría de las reglas mnemotécnicas tienen en común también, el otorgar un sentido a un material de aprendizaje que por sí mismo, carecería de organización y de significado.

Seguidamente ofrecemos algunos ejemplos de estrategias, técnicas, recursos o sistemas mnemotécnicos. En cada uno de ellos analizamos brevemente sus características y sugerimos una aplicación práctica a nuestro contexto.

\section{Sistema de asociación número rima}

Higbee (1977:210) ilustra esta técnica mediante un ejemplo muy popular en inglés que citamos aquí íntegramente: « one is a bun, two is a shoe, three is a tree, four is a door, five is a hive, six are sticks, seven is heaven, eight is a gate, nine is a fine, ten is a hen.»

Este sistema de asociación entre números y palabras rimadas se conoce en inglés como «The Peg Method», término que en castellano se traduce literalmente como método de las perchas . El origen de este nombre lo encontramos en el hecho de que las palabras sirven en realidad como perchas mentales en los que la persona "cuelga» los elementos que quiere memorizar. Esta técnica se utiliza en la vida cotidiana para recordar, bien una lista de actividades que se desea realizar o para memorizar listas de diez palabras no relacionadas en el orden adecuado. Así por ejemplo, si queremos acordarnos de que tenemos que comprar una lista de cosas diversas como pan, un cepillo de dientes, una medicina en la farmacia y el periódico, para no olvidarnos de nada, simplemente podemos asociar cada una de estas cosas con un número y su correspondiente palabra rimada. Para ello, procederemos a colocar de forma ordenada cada elemento de nuestra lista en su correspondiente « casillero», es decir, el número y la palabra rimada. Para que la técnica surta un mayor efecto, los investigadores aconsejan utilizar imágenes con detalles extravagantes o inverosímiles, de modo que produzcan una impresión indeleble en nuestra mente. Por ejemplo, si queremos comprar primero el pan, nos imaginamos con el número uno, un pan gigante de color amarillo fosforecente sobre un bollito diminuto.

Los fundamentos de las cualidades de esta técnica radican en la participación de los sentidos del oído y de la vista. El primero se basa en el gran atractivo de la rima y su capacidad evocadora. La vista interviene en la asociación que se realiza entre la imagen y la palabra. A todo esto hay que añadir el hecho de que al intentar asociar algo con un número, una palabra y una imagen, lo que hacemos es fijarnos más en lo que 
queremos memorizar, lo cual, a su vez, se traduce en un mayor esfuerzo de nuestra mente, que es lo que en definitiva nos permite retener de una forma permanente.

Aunque en principio esta técnica puede parecer extraña por no ser nada habitual en nuestro campo, creemos que tras su oportuna transformación, puede convertirse en un recurso útil y divertido para el aprendizaje y la enseñanza del vocabulario inglés; por esta razón, presentamos a continuación una posible aplicación de la misma en esta asignatura.

Imaginemos que deseamos aprender o enseñar las siguientes palabras inglesas: «tool, bee, fun, door, tie». Para su memorización podemos utilizar la idea del sistema de enlace número rima y aprenderlas enlazadas de la siguiente manera: «one is fun, two is a tool, three is a bee, four is a door, five is a tie». Simplemente se trata de emparejar rimadamente las palabras a los números, sustituyendo la palabra rimada original.

Otra posible adaptación de esta técnica a nuestro contexto es utilizar el sistema rima número inglés tal cual, e insertar la palabra a memorizar en una frase significativa. Supongamos que deseamos retener esta lista de palabras: «man, it, leaf, ring, bee, thin, God, iron, straight, lay», para ello, uniremos cada palabra a una frase como en el siguiente ejemplo: «One, the man is eating the bun; two, it is a shoe; three the leaf is in the tree; four there is a ring on the door; five, the bee lives in a hive; six, the stick is thin; seven, God is in heaven; eight, the gate is made of iron; nine, the line is straight; ten the hen lays eggs.»

Esta técnica puede resultar especialmente apropiada en los niveles de educación primaria, puesto que, generalmente los niños disfrutan mucho rimando sonidos y palabras. No obstante, su utilización exige al profesor o al estudiante un conocimiento básico del sistema fonético con objeto de saber emparejar rimadamente las nuevas palabras con los correspondientes números.

\section{Sistema de asociación alfabeto /rima}

Se trata en realidad de una variación de la técnica anterior. Consiste en utilizar el alfabeto inglés en vez de números. Como el número de letras es mayor, su utilización nos brinda más oportunidades de poder rimar palabras. Un sencillo ejemplo de aplicación al inglés es el siguiente: «A is a day, $\mathrm{B}$ is a Bee, $\mathrm{C}$ is the sea... «

\section{Sistema de asociación fonética}

En el aprendizaje del inglés es posible aprovechar la ventaja que nos ofrecen aquellas palabras que por su procedencia latina coinciden en su forma total o parcialmente con el castellano. En estos casos, el origen etimológico de la palabra favorece la deducción y por tanto su traducción.

A pesar de que en las lenguas provenientes de un mismo tronco común, suele ser elevado el número de palabras coincidentes, son mucho más frecuentes las ocasiones en que nos encontramos con términos de distinta fuente; en el caso del inglés, las palabras de origen germánico pueden ser difíciles de memorizar mediante una imagen exacta, especialmente, si no se sabe el significado de la palabra.

Para las situaciones en que se desconoce el significado de la palabra del inglés y la forma no aporta ninguna pista fiable, Witty (1992) propone utilizar la «Técnica de las palabras semejantes». En realidad, se trata de encontrar una palabra en la lengua materna cuya forma fonética nos sugiera aquella otra que queremos aprender o enseñar en el idioma. Si por ejemplo, lo que se pretende es que los alumnos memoricen la expresión modal «I'd rather» o, palabras como «fair», «cooker», «nose»,podemos ayudarles a establecer asociaciones fonéticas entre las dos lenguas. Así ,»I would rather" suena parecido a un pueblo de Navarra, próximo a Pamplona llamado Burlada. Los que enseñan en Pamplona pueden aprovechar la próximidad y la sejemanza presentando esta construcción con la siguiente frase: «I'd rather go to Burlada» (preferíria ir a Burlada.) 
Se puede aplicar el mismo procedimiento a la memorización de otras palabras, como «fair" que se parece a «fea» en castellano, «cooker» que nos sugiere la palabra "cuca». Tomando como modelo esta última palabra, podemos imaginarnos una cocina guiñándonos un ojo y repitiendo la siguiente frase a modo de eslogan publicitario: «Cooker, la cocina cuca».

Una alternativa a este sistema es explotar las asociaciones fonéticas de la palabra con otras de su misma lengua, con las que, muchas veces, comparte algunos elementos de significado. Por ejemplo: «speech» se relaciona con "speak», ésta con «spoke», y «spoken», a su vez, «speak» con «speaker», etc.

\section{Palabras asociadas}

Otra forma eficaz de aprender el vocabulario es mediante parejas o series de palabras que guardan alguna relación de contraste, parentesco o formación. En esta tarea resultan especialmente útiles los gráficos, árboles y esquemas visuales.

En realidad, esta técnica de aprendizaje de vocabulario está basada en el método denominado «parejas asociadas». En este método, muy utilizado en el ámbito de la psicología, las palabras siempre se asocian unas a otras, bien en parejas o en grupos. Así por ejemplo, la palabra «snow» nos puede sugerir la palabra «cold»o «white» 0 «winter». La palabra «father" está almacenada en nuestra memoria junto a otras como « mother», «son» 0 «daughter».

La técnica de palabras asociadas ofrece un gran abanico de posibilidades para la clase de inglés. Especialmente, puede ser oportuno utilizarla al principio o final de una actividad como revisión del vocabulario. Para ello, pediremos a los alumnos que en breve espacio de tiempo escriban en su cuaderno cuantas palabras le sugiera una determinada palabra. A este respecto, conviene tener presente que las asociaciones de palabras pueden variar de una persona a otra. Por tanto, es una técnica que se adapta más a las situaciones individuales que para el grupo o trabajo en parejas.

\section{Historias sencillas}

En opinión de Baddley (1982), está comprobado científicamente que si hay una historia que relacione las palabras, éstas se recuerdan mejor, porque las asociaciones mentales son más fáciles y más eficaces cuando las relacionamos con un sentido. Traducido al aprendizaje de un idioma, este hecho implica que una frase insertada en un contexto significativo se retiene mejor que una palabra aislada. Si por ejemplo, queremos aprender las palabras: «shoe», «toilet», «princess», «carrots», procederemos a inventar una historia que las relacione de algún modo. Nuestra pequeña historia puede resultar en algo parecido a lo siguiente: "The princess of carrots lost her shoe in the toilet. This toilet was in the moon». (la princesa de las zanahorias perdió su zapato en el lavabo. Este lavabo estaba en la luna ). Una vez inventada una historia, el paso inmediato es leerla en voz alta y repetirla con la mayor exactitud posible.

\section{Sistema de los Lugares}

Esta técnica se conoce también como itinerarios, topográficos, técnica de los lugares, memorización ordenada y sala romana. En realidad, las numerosas acepciones hacen referencia a una de las técnicas más antiguas, empleadas en sus discursos por griegos y romanos. Hoy en día, se emplea para recordar algo de forma ordenada, mediante la utilización de lugares previamente conocidos que sirven como imágenes de enlace. Como señala Gauquelin (1987), los seres humanos tenemos un conocimiento casi instintivo de los sitios que habitamos o en que hemos vivido. Nuestros lugares están cargados de connotaciones afectivas que nunca nos abandonan. Frecuentemente nos imaginamos recorriendo las habitaciones de una casa, un parque, una calle, etc. Lo 
que se propone en esta técnica es imaginar un lugar familiar y definir de modo claro un itinerario de puntos concretos en los que seguidamente colocaremos mentalmente lo que deseamos memorizar. Para recordar, recorremos mentalmente los puntos de nuestro lugar ficticio, visualizando los objetos que hemos colocado en ese lugar.

La precisión y el orden son requisitos esenciales en este sistema mnemotécnico. En inglés puede ser apropiado para enseñar y aprender sistemas de palabras en las que el orden es importante como por ejemplo: nexos de enlace, días de la semana, meses del año, ordinales, vocabulario de la casa, etc. Un posible ejercicio de aplicación puede ser el siguiente:» The hammer is in the kitchen, the screwdriver is in the living-room, the pliers are in the bathroom, etc..."

\section{Agrupamiento espacial}

En opinión de Lowar (1990), un modo de mejorar nuestra memoria es a través de la realización periódica de ejercicios de coordinación. Entre ellos, el distribuir palabras en columnas y ejercitarse en repasarlas rápidamente, es uno de los más sencillos de adaptar al aprendizaje del inglés. Esta actividad puede ser especialmente útil si se cierran los ojos y se repiten las palabras en voz alta siguiendo el orden en que han sido escritas, y tratando de imaginarse su forma. Igualmente, a la hora de lograr que la memoria «fije» el vocabulario, la distribución de palabras en una hoja, de manera que compongan figuras geométricas, esquemas, gráficos, o en varias columnas en vez de una sola, parece ser un recurso más efectivo que la distribución tradicional en una única lista.

Ejemplo de aplicación:

$\begin{array}{cc}\text { voice stupid } & \text { flower picture } \\ \text { cloud smile } & \text { coat stair } \\ \text { glad } & \text { leaf }\end{array}$

\section{Uso de imágenes}

La utilización de fotografías o dibujos resulta más eficaz que la equiparación de las palabras a sus correspondientes términos en la lengua materna. Tiene además, la ventaja de impedir la posible interferencia entre la lengua materna y la lengua objeto de aprendizaje. Para ello, procederemos a buscar material que represente a las palabras o simplemente, las dibujaremos; este recurso resulta apropiado, especialmente, a la hora de memorizar palabras que denominan objetos, si bien, también puede ser adecuado para retener términos verbales que expresan acciones cotidianas.

Otra alternativa a esta técnica es visualizar mentalmente la palabra. En la mayoría de los individuos, la imaginación se basa en primer lugar, en el sentido visual, después en el auditivo y por último, en el sentido del tacto, el gusto y el olfato. Gauquelin revisa una serie de investigaciones que confirman el hecho de que la información visual es la que mejor se retiene tanto a largo como a corto plazo. $\mathrm{La}$ memoria de imágenes es casi ilimitada; no obstante, conviene tener presente que las imágenes de los objetos son más sencillas de retener que las descripciones verbales de los mismos y, que, las descripciones de los objetos se fijan todavía mejor que los nombres de los mismos. El uso de imágenes reales o mentales puede resultar particularmente adecuado para aquellos individuos que si bien, poseen una memoria verbal pobre, tienen más facilidad para recordar mediante imágenes.

\section{Enumeración}

Esta técnica se conoce en psicología como «Juego de Kin» y ha sido utilizada tradicionalmente por los psicoterapeutas. Desde hace algún tiempo, la encontramos también en los libros de juegos para aprender el vocabulario inglés. Se caracteriza 
por presentar en una mesa diversos objetos durante unos minutos y a continuación, permitir que los vea el sujeto de la experiencia; éste podra tocarlos, observarlos, pero no se le permite tomar notas escritas ni hacer comentario alguno. Seguidamente los objetos se retiran y el individuo debe proceder a la enumeración de los mismos. La utilidad de esta técnica radica en el refuerzo visual que aportamos a la memoria al reconocer objetos y denominarlos mediante palabras. Aunque Baddley cuestiona su valor en psicología, en el campo de la enseñanza del inglés es un buen recurso puesto que refuerza el aprendizaje al tener que visualizar el objeto y posteriormente señalarlo mediante la palabra que le corresponde.

\section{Análisis de las palabras}

Un ejercicio de percepción visual para desarrollar el poder de observación consiste en analizar atentamente la forma de la palabra, primero mediante la visualización global, después desglosándola con objeto de percibir sus grafemas, las partes en las que se compone, número de sílabas etc. Una vez realizado esto, examinaremos la palabra desde otros ángulos como su origen, su forma, sus connotaciones, las semejanzas que presenta respecto a otras que ya conocemos, el tipo de significado, positivo o negativo etc.

\section{Agrupamientos}

Prácticamente, todos los autores de libros sobre técnicas mnemotécnicas que hemos. consultado, coinciden en señalar el hecho de que para retener bien, es mejor organizar los datos conforme a un orden de clasificación, jerarquía o categoría. El cerebro registra con más facilidad lo que está estructurado que aquello que está desorganizado. Además de retenerlo durante más tiempo, lo evoca también con mayor rapidez y fidelidad. Este principio se puede adecuar al aprendizaje y enseñanza del vocabulario inglés, mediante la observación de una regla muy sencilla: «se obtienen mejores resultados en la memorización de palabras si se utiliza algún sistema para agruparlas». Organizar de forma inteligente el aprendizaje del vocabulario significa integrar las palabras en grupos, familias o esquemas de relaciones. Un posible modelo de agrupación lo encontramos en los adjetivos de nacionalidad, en los que podemos observar distintas similitudes ortográficas que sirven como modelo a varios adjetivos: -ish, -an, -ese etc. Otro ejercicio de agrupación que puede realizar el alumno, es clasificar los nombres que denotan oficios de acuerdo a varios criterios como, trabajos al aire libre, frente a trabajos que se desarrollan en interiores; profesiones en las que intervienen distintas partes del cuerpo; oficios en los que se requiere una determinada habilidad; etc.

\section{Cadenas de palabras}

Esta técnica , conocida también como "comparación sucesiva», es útil para memorizar una lista de palabras de forma ordenada. En este sistema, las palabras forman una cadena, de tal manera que cada palabra se asociada con la anterior y a la vez con la siguiente, produciéndose así eslabones sucesivos. Si, por ejemplo, queremos memorizar las palabras inglesas: «brick», «roof», «neighbourhood», «umbrellas», "violet», podemos utilizar la técnica de encadenamientos y proceder a su memorización de la siguiente manera: «Nowadays there are a lot of bricks. Bricks are on the roofs. Roofs are in my neigbourhood. In my neighbourhood there are a lot of umbrellas. The umbrellas are violet. Violet is not my favourite colour. In fact, I hate it. «

\section{Recursos auditivos}

Dentro de los recursos auditivos, la recitación es especialmente interesante a la hora de aprender vocabulario en un idioma. Está comprobada empíricamente la efi- 
cacia de leer en voz alta la materia aprendida frente a una simple lectura silenciosa. Lowar menciona varias investigaciones en las que se hace referencia al hecho de que, los individuos que utilizan la recitación, recuerdan por término medio más palabras, que aquellos que no emplean este recurso. La lectura en voz alta implica una participación mucho más activa por parte del individuo al tener que concentrarse en lo que lee y cómo lo lee. Desde esta perspectiva, es ya de por sí una buena práctica, pero ofrece sin duda más ventajas. En primer lugar, nos permite familiarizarnos con palabras y estructuras y asociarlas a un contexto significativo; en segundo lugar, nos proporciona de inmediato la información de nuestros progresos, lo que a su vez es ya un excelente estímulo para seguir adelante.

La adaptación de esta técnica al aprendizaje del inglés no exige más requisito que la voluntad de ponerla en práctica de manera sistemática. La recitación se acopla a todas nuestras necesidades como lectura de textos cortos, pasajes largos, poemas, frases e incluso palabras. En cualquier caso, para obtener el máximo rendimiento de esta técnica es aconsejable seguir unos pasos metódicos. En primer lugar , leer la materia en voz alta un par de veces tratando de reproducir una imprensión exacta; en segundo lugar, cerrar los ojos y tratar de repetir de memoria la información.

\section{CONCLUSIONES}

En este artículo hemos pretendido ofrecer algunos ejemplos de aplicación de estrategias de aprendizaje del vocabulario basadas en la utilización consciente de la memoria. Ciertamente, el uso de las técnicas y recursos mnemotécnicos no es el único camino a seguir para tratar de conseguir este objetivo. Aprender una palabra exige desde luego una memorización previa; pero no hay que olvidar tampoco que el alumno deberá dominar otros aspectos importantes como el uso correcto de las palabras en distintos contextos significativos.

Las técnicas mnemotécnicas no son, en modo alguno, la receta mágica para conseguir el éxito en la dura tarea de aprender y enseñar un idioma. En principio, exigen a quien las utiliza un cierto grado de esfuerzo y una buesa dosis de constancia.

Por último, es necesario señalar que el uso de técnicas mnemotécnicas en el aprendizaje del vocabulario inglés no es sinónimo de frivolidad o ligereza en el aprendizaje. Por el contrario, suele ser un indicativo de cultura e inteligencia por parte de quien las utiliza, al saber aprovechar los recursos que disponemos para facilitar la tarea de aprendizaje de una lengua extranjera. En última instancia, son además de eficaces, prácticas, puesto que no podemos olvidar el hecho de que en nuestro contexto educativo, las pruebas académicas se basan siempre en conocimientos previamente memorizados.

\section{Referencias}

ATKINSON, R. C. (1975). «Mnemotechnics in second-language learning». American Psycbologist, 30, 821-828.

BADDELeY, A. (1982). Your Memory. Londres: Sidgewick and Jackson. Multimedia Publications.

BELEZA, F. S. (1981). «Mnemonic devices: Classification, characteristics, and criteria». Review of Educational Research, 51, 247-275.

BURT, M., y C. KIPARSKY, (1972). The gooficon. A repair manual for English. Rowley, Mass: Newbury House.

BUZAN, T. (1987): Use your Memory. Londres, BBC Publications.

CARRELL, P. L. (1992). «Awareness of text structure: effects on recall». Language Learning, Vol. 42, n. ${ }^{\circ}$ $1,1-20$.

Chauchard, P. (1985). Connaissance et maitrise de la mémoire. París: Centre d'Erude et Promotion de la Lecture. (Versión española: Conocimiento y dominio de la memoria. Bilbao: Ediciones Mensajero.)

GaIRNS, R., y Redman S. (1991). Working with Words. Cambridge: Cambridge University Press. 
Gauqueln, F., (1987). Developper sa Memoire. Métbode Richaudeau. París, Editions Retz. (Versión española: Desarrolle su memoria. Método Richaudeau. Bilbao, Ediciones Mensajero.)

HENNING, G. (1973). «Remembering foreign language vocabulary: Acoustic and semantic parameters". Language Learning, Vol, 23, n. $^{\circ} 2.185-98$.

HERNÁNDEZ PINA, F. (1990). Aprendiendo a aprender: Métados y Térnicas de Estudio para alumnos de E.G.B.B.U.P.-F.P. Murcia: Grupo Distribuidor Editorial.

HIGBeE, K. (1977). Your Memory. How it works and How to improve it. Nueva York: Prentice Hall Press.

JiMÉNEZ, R. (1992). Emores en la producción escrita del inglés y posibles factores condicionantes. Madrid: Editorial de la Universidad Complutense. Colección Tesis Doctorales 73/92.

Levine, A, y Reves T.(1990). "Does the Method of Vocabulary Presentation Make a Difference ?" TESL Canada Journal. Vol. 8, n. ${ }^{\circ} 1.37-51$.

LINDEL, E. (1973). "The four pillars: on the goals of foreign language teaching". En J. Svartvik (Ed.): Errata: Papers in Error Analysis. Lund: CWK Gleerup. 90- 101.

LOWAR, L. (1990). Cómo desarrollar la memoria. Barcelona: Editorial De Vecchi.

MaiguashCA, R. (1993). "Teaching and Learning Vocabulary in a Second Language: Past, Present, and Future Directions". The Canadian Modern Language Review. 83-99.

Meara, P. (1984). "The study of lexis in interlanguage». En Davies, Criper y Howatt (Eds.): Interlanguage. Edimburgo: Edinburgh University Press. 225-236.

PRESSLEY, M. (1979). The Keyword Method of Foreign Vocabulary Learning: An Investigation of Its Generability. Washington: Working Paper, n. ${ }^{\circ} 270$. EDRS MF01/PCO2.

RaUGH, M. R., y Atkinson (1975). «A Mnemonic method for the acquisiton of a second-language vocabulary". Joumal of Educational Psychology. Vol. 67. 1-16.

ROCHE, M. (1983). "Choosing the right word. Errores léxicos y lexicología comparada». Actas I Congreso Nacional de A.E.S.L.A. 221-228.

TANG, G. (1991). "The effect of graphic representation of knowledge structures on ESL reading comprehension". Studies in Second Language Acquisition, Vol.14, n. ${ }^{\circ} 2,177-214$.

ThOMPson, I. (1987). "Memory in Language Learning". En R. Wenden (Ed.): Leamer Strategies in Langrage Learning. Londres: Prentice-Hall International English Language Teaching. 43-56.

WANG, A. Y., y ThORMAS, M. H. (1992). "The effect of imagery-based mnemonics on the long-term retention of Chinese characters". Language Learning, Vol. 42, n. ${ }^{\circ}$ 3. 359-76.

WITTY, S. (1992). El libro de la Supermemoria. Madrid: Ediciones Pirámide.

\section{Estrategias mnemotécnicas para la enseñanza y el aprendizaje del vocabulario del inglés Rosa María Jiménez Catalán $C L \& E, 1994,24, p p .79-88$}

Resumen: Partiendo de una lectura extensiva de obras divulgativas sobre la memoria, y, guiados en todo momento por nuestro interés en contribuir a mejorar la calidad de enseñanza del inglés, a través de este artículo, intentamos llevar a cabo una adaptación de los distintos recursos, estrategias y técnicas mnemotécnicas, al aprendizaje y enseñanza de este idioma. Para ello, definimos el significado de los diferentes términos mnemotécnicos, analizamos los fundamentos y características de los mismos y clasificamos los distintos tipos de recursos mnemotécnicos. Seguidamente, proponemos ejemplos de posible aplicación en este contexto de aprendizaje.

Datos sobre el autor: Rosa María Jiménez Catalán es profesora de Didáctica del inglés de la Universidad de La Rioja. Doctora en Filología Inglesa, y profesora agregada de inglés de secundaria. Imparte cursos de formacion de profesorado, y sus áreas de investigación son: factores de aprendizaje del inglés, diseño de materiales didácticos, sociolingüística y análisis de interlengua.

Dirección: Universidad de La Rioja. Departamento de Filologías Modernas. C/ Prolongación de la Cigüeña s/n, 26004 LOGROÑO- LA RIOJA-

C PERMISOS PARA CITAR O REPRODUCIR EN OTRAS FUENTES: Se pueden citar libremente hasta 500 palabras. Para reproducir una porción de texto mayor, figuras o ilustraciones, se deberá pedir permiso por escrito a la revista, especificando el uso al que se destina el texto. En todos los casos, se deberá citar el copyright de CL\&E. En el caso de artículos o textos que hayan sido a su vez reproducidos en $C L \& E$ los interesados deberán dirigirse tanto a los detentadores del copyright original como a $C L \& E$, en el caso de que se quiera hacer uso de la traducción. FOTOCOPIAS: Para todo lo relacionado con el uso mediante fotocopia del material de esta revista, deberán dirigirse a: CEDRO, C/ José Marañón, 10,3. Izda. Tel. 5941575 . Fax 4453567 